\title{
LABORATORY BENCH TO ANALYZE OF AUTOMATIC CONTROL SYSTEM WITH A FUZZY CONTROLLER
}

\author{
Mykola TRYPUTEN $^{1}$, Vitaliy KUZNETSOV ${ }^{2}$, Valeriy KUZNETSOV ${ }^{3}$, Yevheniia KUZNETSOVA ${ }^{4}$, \\ Maksym TRYPUTEN ${ }^{5}$, Alisa KUZNETSOVA ${ }^{6}$ \\ ${ }^{1}$ Department of Automation and Instrumentation, Dnipro University of Technology, D. Yavornitsky 19, Dnipro, \\ Ukraine, 49027, nikolay.triputen@ gmail.com \\ ${ }^{2}$ Department of the Electrical Engineering and Electromechanic, National Metallurgical Academy of Ukraine, \\ Gagarina ave., 4, Dnipro, Ukraine, 49600, wit1975@i.ua \\ ${ }^{3}$ Electric Power Department, Railway Research Institute, 50, Chlopickiego str., Warsaw, Poland; \\ vkuznetsov@ikolej.pl \\ ${ }^{4}$ Department of Humanitarian, Fundamental and General Engineering Disciplines Institute of Integrated \\ Education National metallurgical academy of Ukraine, Gagarina ave., 4, Dnipro, Ukraine, 49600, \\ wit_jane2000@i.ua \\ 5, 6 Department of Calculating Mathematics and Mathematical Cybernetics, Oles Honchar Dnipro National \\ University, D. Yavornitsky ave., 35, Dnipro, Ukraine, 49600, triputen2014@i.ua, alisa20002014@i.ua
}

\section{Abstract}

The paper represents laboratory bench to analyse a system of automated control with a fuzzy controller. The laboratory bench consists of a thermal object, and software and hardware complex involving logic controller VIPA System 200 V as well as HMI / SCADA system Zenon Supervisor 7.0. The thermal object is described with the help of the second-order differential equation using "current value within the power converter of electric heater-air temperature inside a thermal object" control channel. Coefficients of the differential equation depend upon location of a dampener and upon rotation frequency of a centrifugal fan.

Control error (ie deviation between the specified temperature value within the thermal object and its current value), and derivative of the error, represented in the form of linguistic variables involving five triangular terms and two trapezoidal (extreme) ones have been used as the input values of the fuzzy controller. Output value of the fuzzy controller is the electric power supplied to the electric heater and assuming seven specified values. Selection of the specific value of electric power depends upon knowledge base being a finite set of rules of fuzzy sets falling into line with the applied linguistic variables.

To implement such a system of automated control with a fuzzy controller, original software has been developed making it possible to analyze a process of thermal object heating with the use of human-computer interface. Interaction algorithm of certain program elements has been described. Experimental results, concerning the thermal object transfer from different initial conditions to terminal ones, have been demonstrated. A dependence of mean-square error of the controlled value upon the control period has been demonstrated.

Keywords: laboratory bench, thermal object, hardware-software complex, programmable logical controller, dynamic model.

\section{RELEVANCE}

Currently, there are a large number of automation objects in industry, the management of which by traditional methods is impossible due to insufficient information in terms of their properties, useful signals and noise acting on them. The presence of uncertain or fuzzy information leads to the fact that traditional quantitative methods used in the theory of automatic control are not effective enough [1]. As a result, difficulties arise in the identification of the automation object and the formation of control algorithms for them. One of the ways to overcome these difficulties is to use fuzzy concepts and knowledge, conduct operations using fuzzy logical rules and obtain fuzzy conclusions based on them that allow to generate sequences of actions on a managed object [2-4].

In the scientific literature, much attention is paid to the mathematical and physical modelling of control systems with a fuzzy controller or control algorithm. In [5-7] were studied fuzzy control structures for nonlinear objects of various physical nature in the SIMULINK MATLAB environment. As a result of computational experiments was shown a control efficiency. However, there is no information on the relationship between the values that determine the effectiveness of control, and the values that characterize the features of the control actions. This complicates the choice of technical means for the implementation of control systems, as well as the organization of interaction of control 
tasks with other tasks that can be solved using the selected computing system.

In $[8,9]$ were performed a physical modelling of control systems with a fuzzy controller. However, the lack of a human-machine interface with the possibility of operational influence on the conditions of the experiment and visualization of changes in input and output values in a convenient form for the researcher in the on-line mode complicates the conduct of wider and deeper studies. In addition, these physical models cannot be used as laboratory stands for the training of qualified personnel who possess modern knowledge and practical skills in the synthesis and analysis of automatic control systems (ACS) for various purposes, including the management of automation objects.

Nowadays, the laboratory base of scientific and educational institutions is being updated with the use of technical products of world famous companies such as: Siemens, ABB, Moeller, Shneiderelectric [10]. The use of modern devices allows you to create effective laboratory and diagnostic stands for solving the problems of preparing future competitive engineers in the field of automation and for solving the problems of testing of modern technological process control systems [11, 12]. However, laboratories created in this way have disadvantages - low adaptation to the research and lack of methodological support.

\section{FORMATION OF OBJECTIVES}

It is required to improve the efficiency of laboratory facilities use for learning at the expense of their adaptation to solving problems of synthesis and analysis of ACS with fuzzy controller. Objective is to develop ACS by means of a thermal object with fuzzy controller to solve training problems.

The Department of Automation and Instrumentation of the Dnipro University of Technology has implemented a laboratory bench (Fig. 1) being hardware-and-software complex, and involving thermal controlled object; and hardware, and software for the automated control system [1316] which makes it possible to study and analyse the automatic systems implementing different control strategies.

The laboratory stand consists of three main zones: - the chamber in which the process of heating is carried out; - control, adjustment and display panel; - the panel of the controller, power supply units and actuators.

The chamber (Fig.2) consists of flow-though rectangular prism shaped container, centrifugal blower, suction flue, electric heater, screen and thermal converter. Centrifugal blower and suction flue are located on the opposite sides of the container. Electric heater, screen and resistance temperature device are located between them.
Centrifugal blower provides continuous cold air supply from environment inside thermal unit. Depending upon screen position, suction blower engine rotation frequency and electric capacity applied to heating element, air warms up to a certain temperature [17-19]. Air temperature variation is controlled with resistance temperature device.

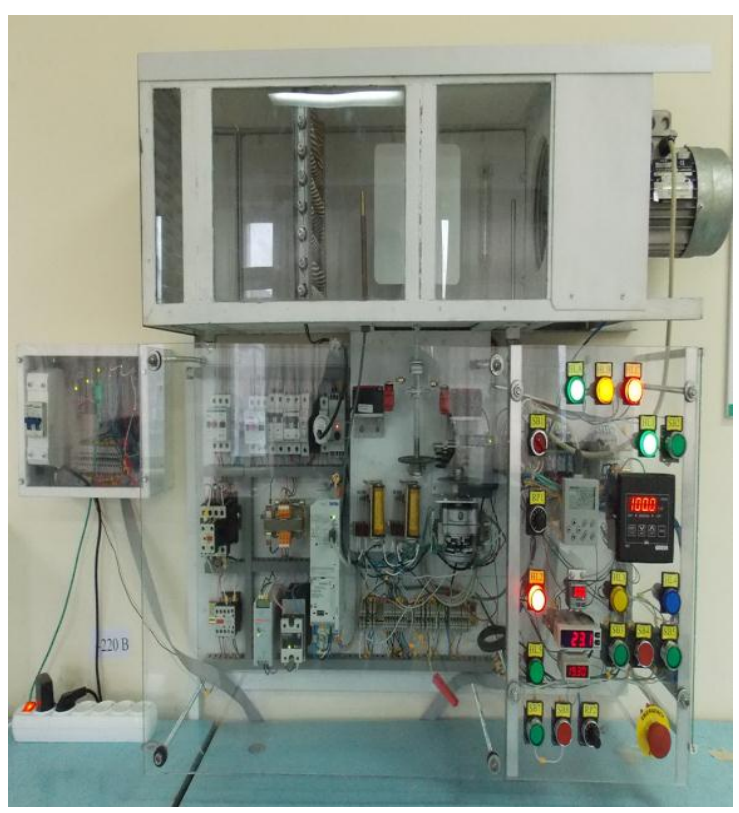

Fig. 1. Appearance of the laboratory bench

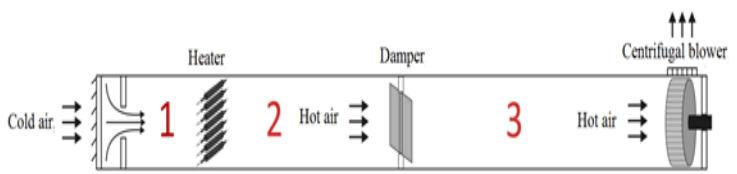

Fig. 2. Schematic representation of the working areas of the chamber

Hardware component of automatic control system has been developed on the basis of VIPA System $200 \mathrm{~V}$ programmable logic controller (PLC) The structure of hardware component is shown on Fig. 3. PLC in automatic control system serves as remote analogue input / output module [20-21].

The Vipa System 200V programmable logic controller is one of the most advanced VIPA controller family. They are used in industrial automation systems with increased requirements for equipment reliability and for the time parameters of control loops. The CPUs are compatible by a set of instructions with the popular SIMATIC S7-300 controllers and can be programmed using WinPLC7 software (VIPA) or STEP 7 (Siemens).

The System 200V series is built on a modular basis, which allows you to optimally select the configuration for a specific task and easily modify the system when it is expanded or changing its requirements.

All I / O modules and interface modules are universal, which allows you to combine them with any CPU in this series. At the same time, it is 
possible to choose a processor module with optimal performance for solving the control problem.

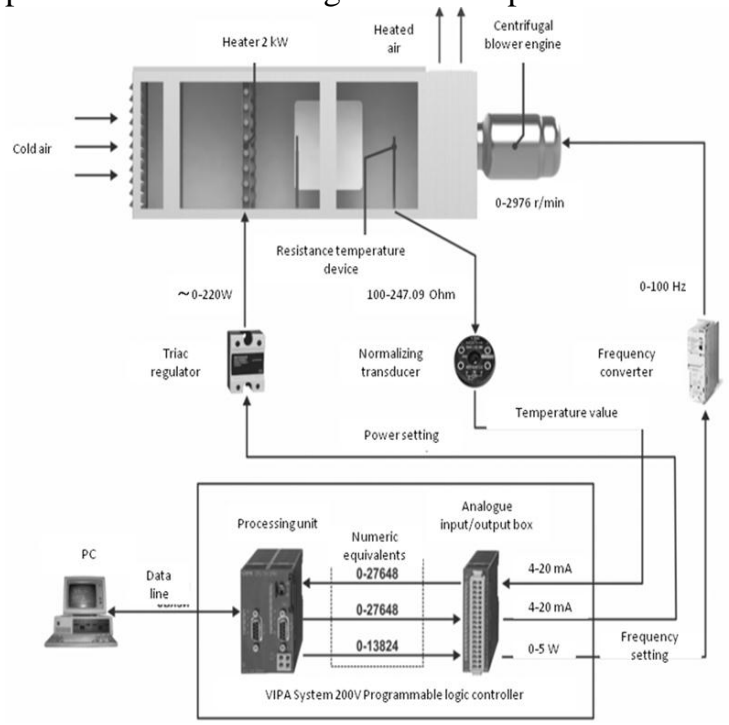

Fig. 3. Structure of automatic control system

The VIPA System 200V Series controllers have good response times and are suitable for controlling batch, continuous and batch production.

Table I shows the automation equipment of a laboratory bench.

Table I. Automation Tools

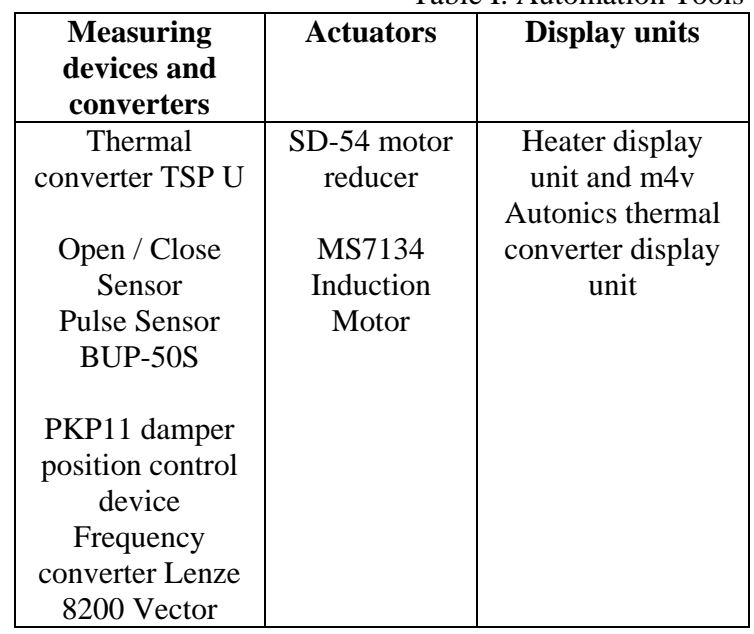

The software component of ACS includes software of programmable logic controller designated for arrangement of calculation processes and software of personal computer on the basis of HMI / SCADA of Zenon Supervisor 7.0 system for the purposes of human-machine interface and various types of regulators implementation.

Zenon is a software and hardware package for creating automation systems produced by the world leader in HMI / SCADA solutions, COPA-DATA. This software and hardware complex is focused on solving the problems of process visualization, machine operations and production management. It offers simple object-oriented design, full compatibility and integration into a single automation system of various devices, from individual terminals to dispatch control points with redundancy. Zenon\&\#39;s openness allows you to quickly implement a reliable connection with any hardware or software, works perfectly on industrial PCs and devices with Windows CE.

This bench provides settlement of a wide range of tasks related to study of technical automation systems facilities, research of identification methods and principles of technological objects control, acquiring of practical skills of automatic system programming in real-time scale [22-24]. However, basic hardware and software facilities of laboratory bench do not provide fuzzy ACS research what limits its application for educational purposes.

Fig. 4 demonstrates thermal object as a control object.

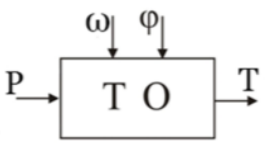

Fig. 4. Structure of the thermal object

In this context: $T$ is temperature inside the object (ie controlled value); $P$ is power supplied to the electric heater (ie controlling value); $\omega$ is rotation velocity of asynchronous motor (i.e. exciting value); and $\varphi$ is location of a dampener (i.e. exciting value).

The separation of input values into controlling values and exciting ones is not terminal since they may change over depending upon the research objective.

Dynamic model of the thermal object along "current value within power converter of electric heater-air temperature inside a thermal object" control channel (rotation frequency of a centrifugal fan is $50 \mathrm{~Hz}$; the dampener is in a fully open position) is the second- order aperiodic link [13].

Fuzzy controller is represented in the form of the three units: fuzzifier, area of fuzzy logics, and defuzzifier (Fig.5) [25-27].

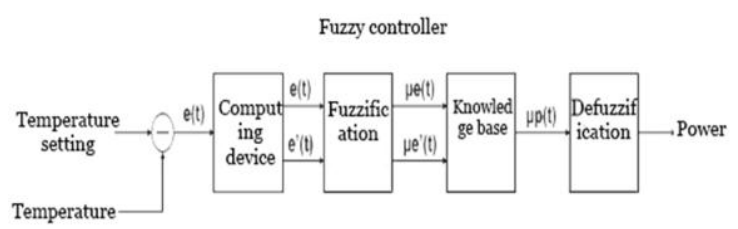

Fig. 5. Structure of the thermal object

Controlling error $e(t)$, calculated as a difference between the specified temperature value and actual temperature within the thermal object, and velocity $e^{\prime}(t)$ of the error variation, calculated as difference between the current errors and during previous period respectively are the input values of the fuzzy controller.

The values are developed within the computing device getting then to the fuzzification unit terminal where they obtain specific values of membership 
functions $\mu e(t)$ and $\mu^{\prime} e(t)$ of corresponding linguistic terms. At the stage, fuzzy controller operates with linguistic variables. According to the obtained terms, knowledge base formulates fuzzy logical conclusion transmitted to a defuzzification unit in the form of linguistic variable Power and degree of its membership $\mu p(t)$. Defuzzification translates the fuzzy value into the absolute power value supplied to an executive unit (ie electric heater).

The fuzzification stage determines correlations between numerical values of input variables of controlling error, its variation velocity, and values of membership values of terms of linguistic variables corresponding to them.

Each linguistic variable is represented with the help of seven terms - five triangular terms, and two trapezoidal ones. Table II explains variation ranges of the input values.

Table II. Variation ranges of the input values

\begin{tabular}{|c|c|c|}
\hline Input value & $\begin{array}{c}\text { TEXT_MINIMU } \\
\text { M_VALUE }\end{array}$ & $\begin{array}{c}\text { TEXT_MA } \\
\text { XIMUM_V } \\
\text { ALUE }\end{array}$ \\
\hline Error & $-10^{\text {about }}$ WITH & $\begin{array}{l}10^{\text {about }} \\
\text { WITH }\end{array}$ \\
\hline Velocity & $-6^{\text {about }}$ WITH & $\begin{array}{l}6^{\text {about }} \\
\text { WITH }\end{array}$ \\
\hline
\end{tabular}

Figures 6 and 7 demonstrate membership functions of certain terms of linguistic variables Error and Velocity. The terms are specified respectively: LN - large negative ; $\mathrm{AN}$ - average negative ; SN - small negative ; $\mathrm{N}$ - normal ; SP - small positive ; $\mathrm{AP}$ - average positive ; and LP large positive.

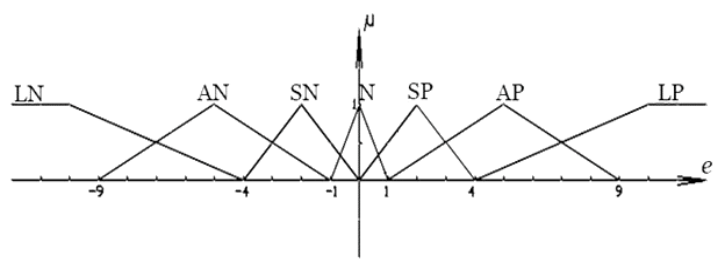

Fig. 6. Terms of set of linguistic variable Error

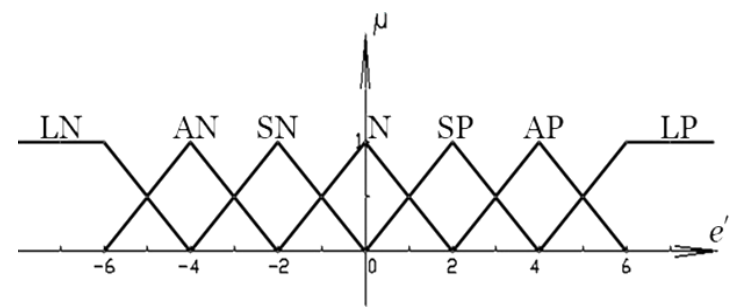

Fig. 7. Terms of set of linguistic variable Velocity

The knowledge base has been formed using rule set of fuzzy products of $A=\square B$ type where $A$ is a condition of core of fuzzy products, $B$ is termination of a core of fuzzy products; and " $=\square$ " is index of a logical consequence.

Table III represents the fuzzy production rules derived as a result of processing of expert knowledge, concerning the controllable object, accumulated by the Department academics and students.

Table III. knowledge base

\begin{tabular}{|c|c|c|c|c|c|c|c|}
\hline$e / e^{\prime}$ & LN & AN & SN & No & SP & AP & SP \\
\hline LN & LN & LN & LN & LN & LN & LN & LN \\
\hline AN & LN & LN & LN & LN & CO & SN & SN \\
\hline SN & LN & LN & AN & MO & No & No & SP \\
\hline No & LN & AN & SP & SP & AP & LP & LP \\
\hline SP & SN & SP & AP & LP & LP & LP & LP \\
\hline AP & AP & AP & LP & LP & LP & LP & LP \\
\hline SP & LP & LP & LP & LP & LP & LP & LP \\
\hline
\end{tabular}

In the context of the Table III, values of linguistic variables Error and Velocity are conditions of cores (labels of rows and columns respectively). Core termination is at the intersection of the rows and columns corresponding to the linguistic variable Power. Physical value of Power varies within 0\% -100\% range.

In terms of one controlling variable, transformation of its linguistic value into a physical value (i.e. defuzzification process) is not complicated. Table IV represents the transformation results.

Table IV. Correspondence between linguistic values of Power variable, and its physical values

\begin{tabular}{|c|c|c|c|c|c|c|c|}
\hline $\begin{array}{c}\text { Terms of } \\
\text { linguistic } \\
\text { variable } \\
\text { Power }\end{array}$ & Z & Z & $Z_{\Omega}$ & $\stackrel{2}{z}$ & $\tilde{n}$ & $\frac{2}{<}$ & a \\
\hline $\begin{array}{l}\text { Values of } \\
\text { quantity of } \\
\text { Power } \\
\text { value }\end{array}$ & 0 & $\begin{array}{l}n \\
0 \\
0\end{array}$ & $\begin{array}{l}\stackrel{n}{m} \\
m \\
m\end{array}$ & in & $\begin{array}{l}n \\
\dot{0} \\
\dot{8}\end{array}$ & $\begin{array}{c}\tilde{m} \\
\tilde{\infty}\end{array}$ & 8 \\
\hline
\end{tabular}

Implementation of ACS with fuzzy controller involved the development of original software operating within WinPLC7 environment, and making it possible to analyse a process of thermal object control in terms of different values of specifying data as well as exciting data with the use of human-computer interface. The software actualizes sequence of operations in accordance with the algorithm shown in Figures 8. and 9 explains the human-computer interface with $10 \mathrm{~s}$ controlling procedure.

Figures 10 and 11 represent the results of the experiments in terms of the heat object control for control periods of $10 \mathrm{~s}$ and $70 \mathrm{~s}$ respectively.

Table $\mathrm{V}$ demonstrates dependence of the mean square deviation of control error $\delta_{\varepsilon}$ on control period $T_{c o n}$ calculated according to the experimental data obtained during the experiments in terms of a heat object. Experimental data were registered in each $0.1 \mathrm{~s}$. Mean square deviations of the control error are determined according to [28]:

$$
\delta_{\varepsilon}=\sqrt{\frac{\sum_{1}^{n}\left(T_{i}-T_{z}\right)^{2}}{n-1}},
$$


where $n$ is the sample volume; and $T_{i}$ and $T_{z}$ are temperature value and the specified temperature value respectively.

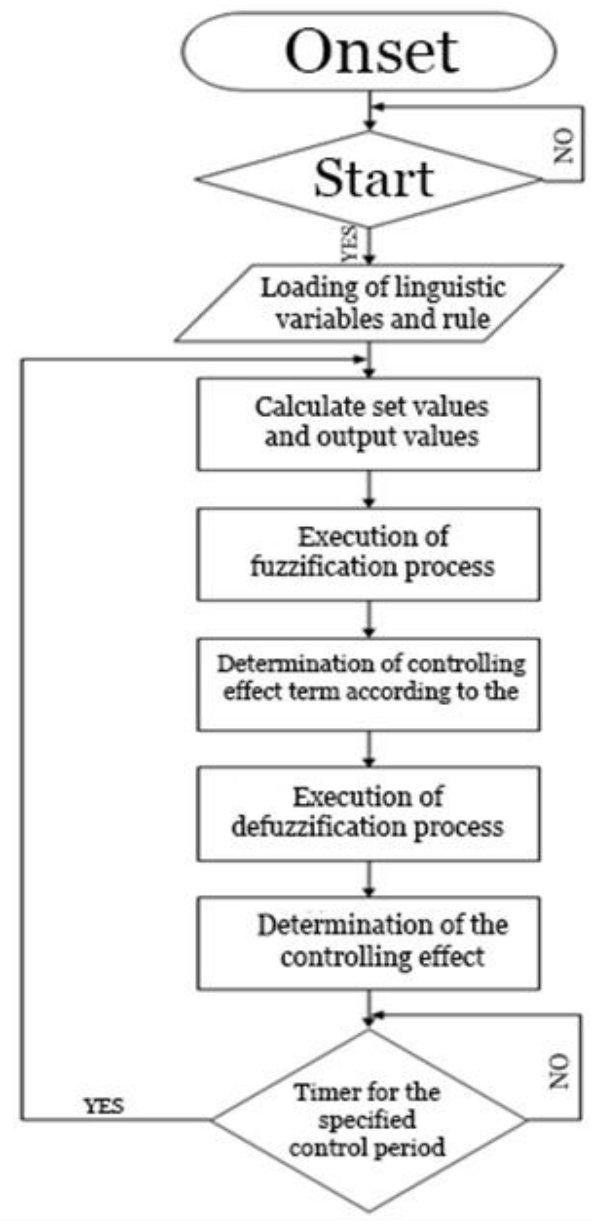

Fig. 8. control algorithm

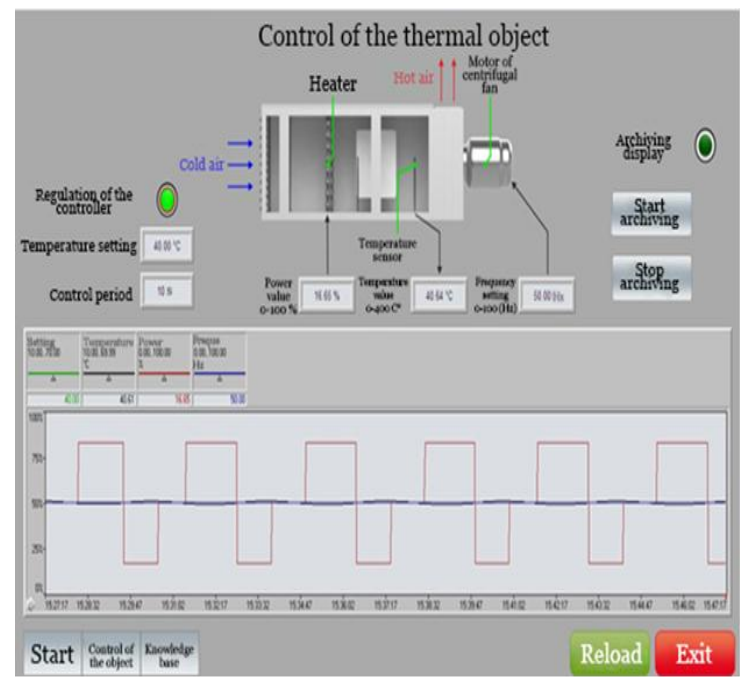

Fig. 9. Human-computer interface

According to the data given in Table $\mathrm{V}$, the normalized correlation coefficient $r_{\delta_{\varepsilon}, T_{c o n}}$ was calculated to reveal the linear relationship between the $T_{c o n}$ values by the method given in [28]. The result of the calculations are given in Table VI.

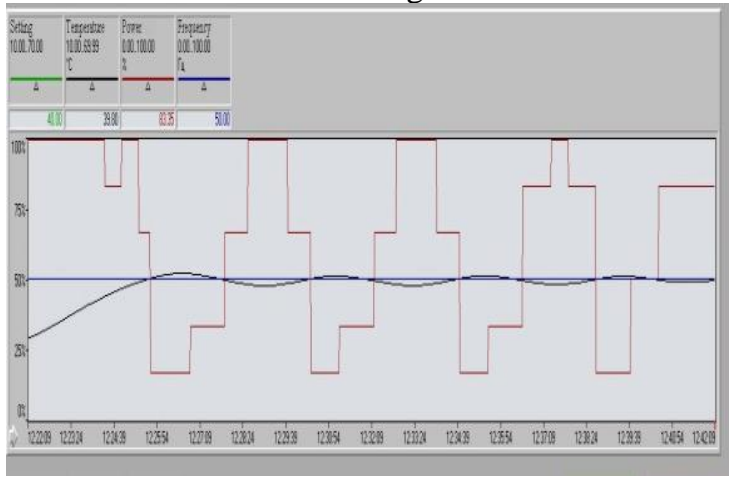

Fig. 10. The result of the experiment for $\mathrm{T}_{\mathrm{con}}=10 \mathrm{~s}$

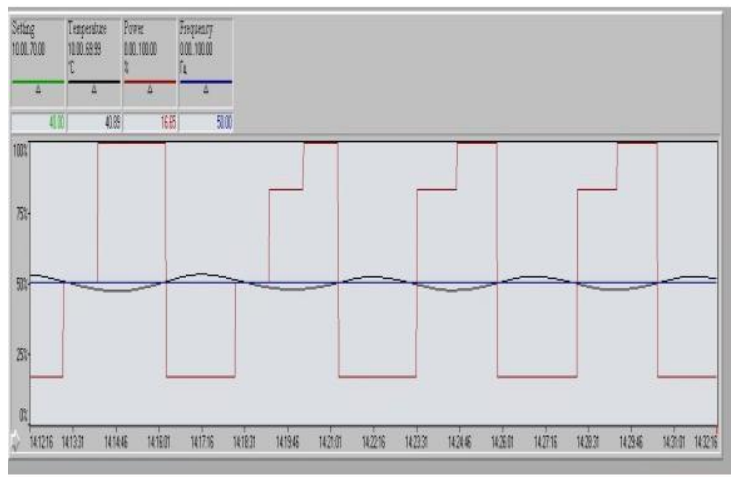

Fig. 11. The result of the experiment for $T_{\text {con }}=70 \mathrm{~s}$

Table V. Dependence of a mean-square error upon

\begin{tabular}{|c|c|c|c|c|c|c|c|c|c|c|}
\hline $\begin{array}{c}T_{c o n} \\
\mathrm{~s}\end{array}$ & 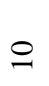 & તి & లి & 아 & in & 8 & $?$ & $\triangleright$ & ৪ & 8 \\
\hline$\delta_{\varepsilon}$ & F. & ñ & $\stackrel{m}{0}$ & ڤ̊ & $\stackrel{\circ}{\circ}$ & $\stackrel{\Omega}{=}$ & $\stackrel{m}{\dddot{m}}$ & $\stackrel{0}{\text { fo }}$ & & \\
\hline
\end{tabular}

Table VI. The Results of the Calculation of the Normalized Correlation Coefficient

\begin{tabular}{|c|c|c|c|c|}
\hline & $\begin{array}{l}\text { Average } \\
\bar{\delta}_{\varepsilon}, \bar{T}_{c o n}\end{array}$ & $\begin{array}{c}\text { Root } \\
\text { mean } \\
\text { square } \\
\text { deviation } \\
\delta_{\delta_{\varepsilon}}, \delta_{T_{c o n}}\end{array}$ & $\begin{array}{c}\text { Cor- } \\
\text { relation } \\
\text { coeffi- } \\
\text { cient } \\
R_{\delta_{\varepsilon}, T_{c o n}}\end{array}$ & $\begin{array}{c}\text { Norm- } \\
\text { lized } \\
\text { correlatio } \\
\mathrm{n} \\
\text { coefficient } \\
r_{\delta_{\varepsilon}, T_{\text {con }}} \\
\end{array}$ \\
\hline$\delta_{\varepsilon}$ & 1.18 & 0.56 & \multirow{2}{*}{16.63} & \multirow{2}{*}{0.98} \\
\hline $\begin{array}{c}T_{c o n}, \\
\mathrm{~s}\end{array}$ & 55 & 30.28 & & \\
\hline
\end{tabular}

Here: $\bar{\delta}_{\varepsilon}$ and $\bar{T}_{c o n}$, are average values of mean square deviation of the control error and control period respectively; $\delta_{\delta_{\varepsilon}}$ and $\delta_{T_{c o n}}$ are the standard deviations of $\delta_{\varepsilon}$ and $T_{c o n}$, respectively; $D_{\delta_{\varepsilon}}$ and $D_{T_{c o n}}$ are the standard deviations of $\delta_{\varepsilon}$ and $T_{c o n}$, respectively; $R_{\delta_{\varepsilon}, T_{c o n}}$ and $r_{\delta_{\varepsilon}, T_{c o n}}$ are the correlation coefficient and the normalized correlation 
coefficient. The normalized correlation coefficient $r_{\delta_{\varepsilon}, T_{c o n}}$ is close to unity, which corresponds to the presence of a liner relationship between the quantities $\delta_{\varepsilon}$ and $T_{c o n}$.

The linear dependence $T_{c o n}=f\left(\delta_{\varepsilon}\right)$ is determined from the following expression [19]:

$$
T_{\text {con }}-\bar{T}_{\text {con }}=r_{\delta_{\varepsilon}, T_{c o n}} \frac{\delta_{T_{c o n}}}{\delta_{\delta_{\varepsilon}}}\left(\delta_{\varepsilon}-\bar{\delta}_{\varepsilon}\right) .
$$

After substitution in (2) of the parameter values from Table VI we get:

$$
T_{\text {con }}-55=0.98 \frac{30.28}{0.56}\left(\delta_{\varepsilon}-1.18\right) .
$$

As a result of identical transformations, we finally have:

$$
T_{\text {con }}=52.99 \delta_{\varepsilon}-7.53 \text {. }
$$

Figure 12 shows graphs of the experimental (red colour) and analytical (blue colour) dependencies $T_{c o n}=f\left(\delta_{\varepsilon}\right)$, respectively, according to the data in Table V and expression (4).

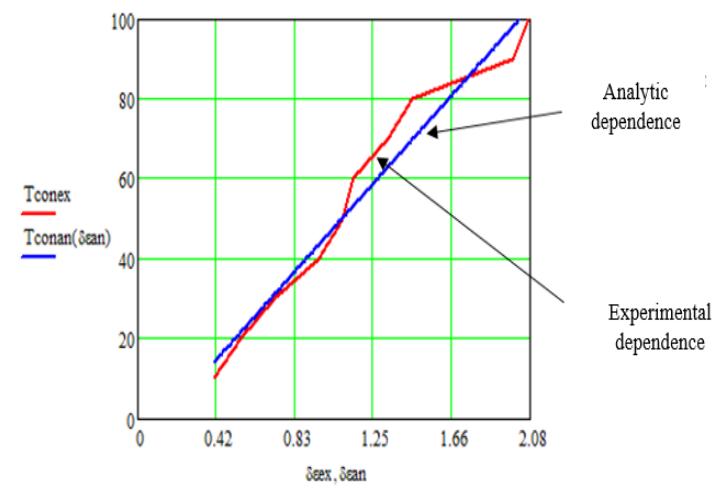

Fig. 12. Graphs of experimental and analytical dependencies $T_{\text {con }}=f\left(\delta_{\varepsilon}\right)$.

\section{CONCLUSIONS}

The paper describes synthesis of ACS with fuzzy controller in the process of thermal object control for the specific rotation frequency of centrifugal fan, and location of a damper. If variation of the parameters takes place then results of the synthesis will be distinct. Namely ACS development for different conditions and its efficiency evaluation is the small research task during experiments carried out with the help of the laboratory bench in the context of "Theory of the automated control" subject.

ACS with a fuzzy regulator may be implemented on the basis of the software and hardware which include programmable logical controller VIPA System 200 V and HMI / SCADA system Zenon Supervisor 7.0. The fuzzy control algorithm and human machine interface have been developed to change the conditions of functioning for a control system during the experiment.
Analytical dependence of the control period upon the control accuracy has been obtained. The dependence may be applied to substantiate the selection of control parameters while distributing computational resources of the software and hardware.

\section{REFERENCES}

1. Chakraborty J, Jayanthi T, Satya Murty, SAV, Thirugnanamurthy, D, Swaminathan, P. Fuzzy logic based feed water flow control model for prototype fast breeder reactor. 2011 3rd IEEE International Conference on Computer Modeling and Simulation (ICCMS 2011): Conference Paper. Mumbai, 2011.

2. Dubovoi VM, Kvietnyi RN, Mykhaliov OI, Usov AV. Modeling and optimization of systems: Textbook. Vinnytsia: TD “Edelweiss” Ltd.; 2017.

3. Kovrygo YM, Novikov PV. Two-channel fuzzy controller to regulate technological parameters under conditions of nonstationary of dynamic characteristics of the controllable object. Automation of technological and business-processes 2019; 11(1): 4-13. Odesa.

4. German EY, Shutynskyi OG, Lysachenko IG, Demenkova SD. Optimal fuzzy controller in the system of carbonization control in sodium carbonate production. Modern information systems. Quarterly scientific and technical journal 2019; 3(2): 14-21. Kharkiv: NTU "KhPI". https://doi.org/10.20998/2522-9052.2019.2.03.

5. Solanke DR, Chinchkhede KD, Manwar AB. Design \& Implementation of Fuzzy Inference System For Automatic Braking System. International journal of Reseach in Science and Engineering 2017; 6(9): 1242-1255.

6. Vichuzhanin V. Realization of a fuzzy controller with fuzzy dynamic correction. Central European Journal of Engineering 2012; 2(3): 392-398. https://doi.org/10.2478/s13531-012-0003-7.

7. Xie X, Long Z. Fuzzy PID Temperature control system design based on single chip microcomputer. Internetional Journal of Online and Biometrical Engineering 2015 11: 29-33. https://doi.org/10.3991/ijoe.v11i8.4881.

8. Singhala P, Shah DN, Patel B. Temperature Control using Fuzzy Logic. International Journal of Instrumentation and Control Systems 2014; Vol.4. \# 1: 1-10. https://doi.org/10.5121 / ijics.2014.4101.

9. Atar KD, Hanamane MD, Patil AR, Mudholkar RR. Embedded fuzzy greenhouse parameter control and central monitoring system. International Journal of Engineering and Management Research 2014; 4( 4): 222-228.

10. Pritchenko OV. The concept of the incentives of small-sized laboratory stands. Electromechanical and saving up systems. Quarterly scientific production journal. 2010; 2(10): 56-61. Kremenchuk: KSU.

11. Adamczak S, Domagalski R, Sender E, Zmarzły P, Gorycki $€$. Research methods and testing stand developed to examine vibrations generated by rolling bearing. Diagnostyka 2016; 17 (1): 41-49.

12. Roczek K, Rogala T. Induction motor diagnosis with use of electric parameters. Diagnostyka 2019; 20 (4): 65-74. https://doi.org/10.29354/diag/113000

13. Tryputen N, Kuznetsov V, Kuznetsova Y. About the possibility of researching the optimal automatic 
control system on a physical model of a thermal object. 2019 IEEE 2nd Ukraine Conference on Electrical and Computer Engineering, UKRCON 2019 - Proceedings: 1244-1248. L'viv, Ukraine https://doi.org/10.1109/ UKRCON.2019.8879830.

14. Mykola T, Vitaliy K, Serdiuk T, Alisa K, Maksym T, Mykola B. One approach to quasi-optimal control of direct current motor. 2019 IEEE 5th International Conference Actual Problems of Unmanned Aerial Vehicles Developments, APUAVD 2019Proceedings: 190-193. https://doi.org/10.1109/APUAVD47061.2019.8943878.

15. Kuzenkov O, Kuznetsov V, Tryputen N. Analysis of phase trajectories of the third - Order dynamic objects. 2019 IEEE 2nd Ukraine Conference on Electrical and Computer Engineering, UKRCON 2019 - Proceedings: 1235-1243. L'viv, Ukraine https://doi.org/10.1109/UKRCON.2019.8879819.

16. Perekrest A, Chornyi O, Mur O, Nikolenko A, Kuznetsov V, Kuznetsova Y. Preparation and preliminary analysis of data on energy consumption by municipal buildings. Eastern-European Journal of Enterprise Technologies 2018;6(8-96);32-42. https://doi.org/10.15587/1729-4061.2018.147485.

17. Pashchenko FF, Kudinov YI, Pashchenko AF, Duvanov ES. Fuzzy quadratic control of thermal object. 2019 1st International Conference on Control Systems, Mathematical Modeling, Automation and Energy Efficiency (SUMMA): 2019:288-293. https://doi.org/10.1109/SUMMA48161.2019.8947607.

18. Kudinov YI, Kelina AY, Pashchenko AF, Pashchenko FF. Optimization of intelligent fuzzy controllers for industrial facilities. 2014 IEEE 8th International Conference on Application of Information and Communication Technologies (AICT):, 2014: 1-3. https://doi.org/10.1109/ICAICT.2014.7035988.

19. Dong Z, Su Y, Yan X. Temperature Control system of the thermal analyzer based on fuzzy PID controller. 2009 Ninth International Conference on Hybrid Intelligent Systems: 2009:58-61. Shenyang,. https://doi.org/10.1109/ HIS.2009.123

20. Shishov OV. Elements of automation systems. Controllers, operator panels, remote access modules: laboratory practice. Direkt-Media, Moscow, Russia Berlin, Germany; 2015.

21. Manual VIPA System 200V. CP Manual HB97E_CP RE 240-1CA21.

22. Banerjee A, Mondal A, Sarkar A, Biswas S. Realtime embedded systems analysis - From theory to practice. 2015 19th International Symposium on VLSI Design and Test. Ahmedabad, 2015, pp. 1-2. https://doi.org/10.1109/ ISVDAT.2015.7208162.

23. Buttazzo GC. Hard Real-time computing systems: predictable scheduling algorithms and applications. Springer Science + Business Media, LLC, New York, 2011:536.https://doi.org/10.1007/978-1-4614-0676-1.

24. Mall Rajib. Real-time systems: theory and practice. Publisher: Prentice Hall; 2009: 242.

25. ;Dwyer A. Handbook of PI and PID controller tuning rules. " 3rd ed. Dublin Institute of Technology; 2009: 624

26. Rajendran M, Kumar G. Comparative Analysis of PI I PID Controller for a Thermal Process Using PLC. b2018 International Conference on Recent Innovations in Electrical, Electronics \& Communication Engineering (ICRIEECE): 28392841. Bhubaneswar. 2018. https://doi.org/10.1109/ICRIEECE44171.2018.9008671
27. Gozim D, Guesmi K, Mahi D. On the elimination of nonlinear phenomena in DC / DC converters using type-2 fuzzy logic controller. Diagnostyka 2018; 19(3): 73-80. https://doi.org/10.29354/diag/93139

28. Gmurman VE. A guide to solving problems in probability theory and mathematical statistics. 2004. 407.

\section{Receivedd 2020-03-14}

Accepted 2020-05-13

Available online 2020-05-19

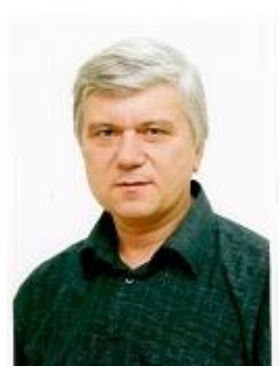

Mykola TRYPUTEN, Phd, Department of Automation and Instrumentation, Dnipro University of Technology. His main interests focused mainly on automatic control systems. In 1993 he began working at the Department of Automation and Computer Systems for an assistant. Since 1994 - Associate Professor.

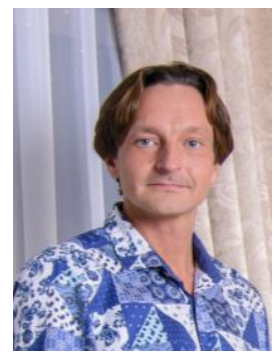

Vitaliy KUZNETSOV, PhD, Department of the electrical engineering and electromechanic, National metallurgical academy of Ukraine. Received $\mathrm{PhD}$ in electrical complexes and systems in 2013. His research interests concern: Induction motors, Modeling, Simulation, and Power quality monitoring systems.

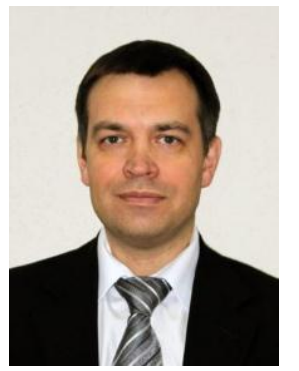

Valeriy KUZNETSOV, prof., dr. hab. Electric Power Department, Railway Research Institute, Poland. Obtained dr.hab. degree in electric transport in 2012. His research interests concern: Energy saving methods, energy management, reliability of traction power supply systems.

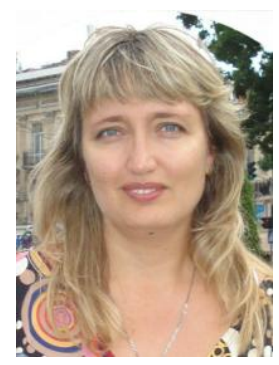

Yevheniia KUZNETSOVA, Senior lecturer of Department of humanitarian, fundamental and general engineering disciplines Institute of Integrated Education National metallurgical academy of Ukraine. Her research interests include Induction motors, Modeling, Simulation. 


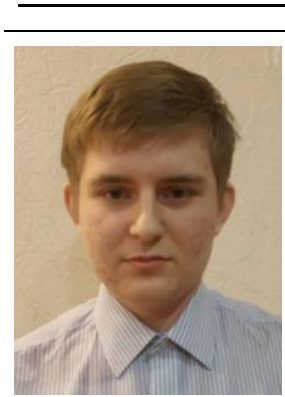

Maksym TRYPUTEN, student of the Department of Calculating Mathematics and Mathematical Cybernetics, Oles Honchar Dnipro National University.

$\mathrm{He}$ is author / Co-author of more than 10 technical papers in international conferences and 1 chapter of Monograph.

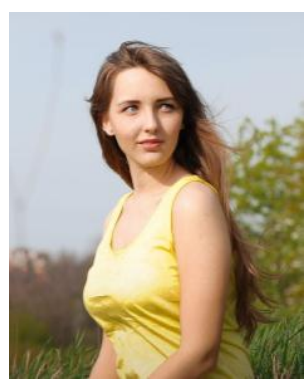

\section{Alisa KUZNETSOVA,}

student of the Department of Calculating Mathematics and Mathematical Cybernetics, Oles Honchar Dnipro National University. She is author / Coauthor of more than 10 technical papers in international conferences and 1 chapter of Monograph. 